\title{
Managed Care after Acute Myocardial Infarction (KOS-zawał) reduces major adverse cardiovascular events by $45 \%$ in 3-month follow-up - single-center results of Poland's National Health Fund program of comprehensive post-myocardial infarction care
}

\author{
Krystian Wita ${ }^{1}$, Andrzej Kułach ${ }^{2}$, Marcin Wita ${ }^{1}$, Maciej T. Wybraniec ${ }^{1}$, Katarzyna Wilkosz ${ }^{1}$, \\ Mateusz Polak', Monika Matla², Łukasz Maciejewski², Joanna Fluder ${ }^{3}$, Barbara Kalańska-tukasik ${ }^{3}$, \\ Tomasz Skowerski², Szymon Gomułka4, Krzysztof Szydło ${ }^{1}$
}

\author{
${ }^{1}$ First Department of Cardiology, School of Medicine in Katowice, Medical University \\ of Silesia, Katowice, Poland \\ ${ }^{2}$ Department of Cardiology, School of Health Sciences in Katowice, Medical University \\ of Silesia, Katowice, Poland \\ ${ }^{3}$ Third Department of Cardiology, School of Medicine in Katowice, Medical University \\ of Silesia, Katowice, Poland \\ ${ }^{4}$ Daily Cardiology Rehabilitation Department, Upper Silesian Medical Center \\ in Katowice, Katowice, Poland
}

Submitted: 8 March 2019

Accepted: 23 April 2019

Arch Med Sci 2020; 16 (3): 551-558

DOI: https://doi.org/10.5114/aoms.2019.85649

Copyright @ 2019 Termedia \& Banach

\section{Abstract}

Introduction: Despite progress in medical and interventional treatment of acute myocardial infarction (AMI) resulting in low in-hospital mortality, the post-discharge prognosis in MI survivors is still unacceptable. The Managed Care in Acute Myocardial Infarction (MC-AMI, KOS-zawat) is a program introduced by Poland's National Health Fund aiming at comprehensive care for patients with $\mathrm{AMI}$ to improve prognosis. It includes acute intervention, complex revascularization, cardiac rehabilitation (CR), scheduled outpatient follow-up, and prevention of sudden cardiac death. The aim of the study was to assess the effect of MC-AMI on major adverse cardiovascular events (MACE) in 3-month follow-up.

Material and methods: In this single-center, retrospective observational study we enrolled 1211 patients, and compared them to 1130 subjects in the control group. After 1: 1 propensity score matching two groups of 529 subjects each were compared. Cox regression was performed to assess the effect of MC-AMI and other variables on MACE.

Results: MC-AMI participation is related to reduced MACE rate by $45 \%$ in a 3-month observation. Multivariable Cox regression analysis revealed MCAMI participation to be inversely associated with the occurrence MACE at 3 months (HR $=0.476,95 \% \mathrm{Cl}: 0.283-0.799, p<0.005)$. Also, older age, male sex $(H R=2.0)$, history of unstable angina $(H R=3.15)$, peripheral artery disease $(H R=2.17)$, peri-MI atrial fibrillation $(H R=1.87)$ and diabetes $(\mathrm{HR}=1.5)$ were significantly associated with MACE.

Conclusions: Participation in MC-AMI - the first comprehensive in-hospital and post-discharge care for AMI patients - improves prognosis and is related to a MACE rate reduction by $45 \%$ as soon as in 3 months.

Key words: Managed Care in Acute Myocardial Infarction, cardiac rehabilitation, myocardial infarction, cardiovascular prevention, major adverse cardiovascular events.

\author{
Corresponding author: \\ Andrzej Kułach \\ Department \\ of Cardiology \\ Medical University \\ of Silesia \\ 47 Ziolowa St \\ 40-635 Katowice, Poland \\ Phone/fax: +48 322527407 \\ E-mail: andrzejkulach@gmail. \\ com
}


K. Wita, A. Kułach, M. Wita, M.T. Wybraniec, K. Wilkosz, M. Polak, M. Matla, Ł. Maciejewski, J. Fluder, B. Kalańska-Łukasik, T. Skowerski, S. Gomułka, K. Szydło

\section{Introduction}

Cardiovascular diseases (CVD) are a leading cause of mortality in Western societies. In Poland, the network of approximately 160 interventional cardiology centers provides primary percutaneous coronary intervention (pPCl) service on a $24 / 7$ basis with $735 \mathrm{pPCl} /$ million inhabitants, thus providing low in-hospital mortality in the acute phase of myocardial infarction (MI). However, the post-discharge mortality in acute myocardial infarction (AMI) patients is high $-10 \%$ after 1 year and almost 20\% after 3 years [1]. European Society of Cardiology (ESC) registries show that the 1-year mortality rate reached $4-12 \%$ and is highly variable across Europe. This is similar to data reported from the USA and European countries [2-4]. The studies suggest that efforts should focus on post$\mathrm{MI}$ care and secondary prevention of CVD [5-7].

The analysis of the post-discharge period shows a particularly high risk of complications within the first several months after MI. The causes comprise insufficient control of risk factors, poor adherence to medication, and the lack of balanced physical activity, which derives mostly from low access to cardiac rehabilitation (CR) programs, as well as poor access to outpatient cardiology care [8-10]. Managed Care in Acute Myocardial Infarction (MC-AMI, KOS-zawat) is a program introduced by Poland's National Health Fund and Ministry of Health aiming at comprehensive care for patients with AMI to improve post-discharge prognosis. It includes acute intervention, complex revascularization, CR, scheduled outpatient follow-up, and prevention of SCD in eligible subjects $[11,12]$.

The aim of the analysis was to assess the relation between participation in MC-AMI and major adverse cardiovascular events (MACE, a composite of death, recurrent myocardial infarction, and hospitalization for heart failure (HF)) in 3-month follow-up. Additionally we assessed the relation between MC-AMI and other clinical variables and MACE in the studied group.

\section{Material and methods}

We present a retrospective analysis from a single, high-volume tertiary cardiology care center.

\section{Study and control group. Principles of MC-AMI}

The study group consisted of all consecutive subjects diagnosed with AMI from 1 Nov 2017 to 31 Aug 2018 who consented to participation in MC-AMI. All patients with AMI, aged > 18 years old who gave informed consent for participation in MC-AMI were included in the unmatched study group. Patients were followed up to 30 Nov 2018. The participation in MC-AMI ensured diagnostics and interventional therapy in AMI according to ESC guidelines (Module I), cardiac rehabilitation (outpatient or in-hospital) (Module II), implantation of ICD or CRT-D in eligible subjects (Module III), and 12-month scheduled, outpatient cardiology care and follow-up (Module IV). The study flowchart is presented in Figure 1. In this analysis only the first 3 months were taken into account. During this period, patients participated in module I, module II, and partially module IV (in most cases visit 1 only). After AMI-related hospitalization, patients who consented to participation in MC-AMI had a screening visit scheduled for 7-10 days after discharge. The screening visit covered clinical assessment by a cardiologist, ECG and basic blood tests (full blood count, $\mathrm{CrCl}$, (RP). Unless contraindicated, patients were then qualified for cardiac rehabilitation (described below), which started not later than 14 days after discharge. Upon CR completion, patients attended visit 1 that was scheduled 6 weeks after discharge from hospital (MI-related hospitalization). During visit 1, clinical assessment and echocardiography was performed to search for patients eligible for implantation of an implantable cardioverter defibrillator (ICD) or cardiac resynchronization therapy (CRT). Additionally, the course of MC-AMI schedule in a particular patient depended on several factors, the most important being staged revascularization (PCI/CABG; in these cases rehabilitation was scheduled after full revascularization) and potential indication for ICD/CRT-D. The 3-month analysis we perform covers module I, II, and the first part of ambulatory follow-up.

The control group consisted of $\mathrm{AMI}$ patients who were hospitalized in our center within 1 year prior to the introduction of the MC-AMI program. Data from all consecutive admissions with AMI diagnosis between 1 Nov 2016 and 31 Aug 2017 were used for analysis. These patients were followed up to 30 Nov 2017.

For initial analysis, we recruited an overall number of 2341 patients with AMI (1211 (51.7\%) patients were enrolled in the study group and 1130 (48.3\%) in the control group). In the study group, there were 69 (5.7\%) in-hospital deaths. Out of the remaining 1142 subjects, 719 (63\%) consented to participation in MC-AMI. In the control group there were 67 (5.9\%) in-hospital deaths and the remaining 1063 patients were analyzed as an unmatched control group.

To reduce selection bias we performed $1: 1$ propensity score matching (PSM) between the study and the control group using pre-specified clinical variables, including age, sex, hypertension, diabetes mellitus, dyslipidemia, smoking, chronic kidney disease, stroke, presentation as ST-elevation myocardial infarction (STEMI), presence of multivessel disease and left ventricular ejection fraction (LVEF). 


\section{AMI-related hospitalization}

Myocardial infarction was diagnosed in line with the Third Universal Definition of Myocardial Infarction. Coronary angiography was performed via either the radial or femoral artery by a standard technique. The stent type used was at the individual operator's discretion. Standard post-MI pharmacotherapy was used according to the European Society of Cardiology recommendations unless contraindicated. Medication is summarized in Table I. Transthoracic echocardiography was performed to assess the left ventricular ejection fraction (LVEF) using the modified Simpson's biplanar method. Chronic kidney disease (CKD) was defined as an estimated glomerular filtration rate $<60 \mathrm{ml} / \mathrm{min} / 1.73 \mathrm{~m}^{2}$.

\section{Cardiac rehabilitation}

Cardiac rehabilitation was preceded by a screening visit (7-10 days after discharge) and performed in an outpatient cardiac rehabilitation facility (22 days) or in-hospital cardiac rehabilitation ward (hospitalization up to 35 consecutive days). The key criterion for in-hospital rehabilitation was $E F \leq 35 \%$ Additionally, patients with serious comorbidities and frailty could be qualified for in-hospital CR regardless of EF.

Follow-up ECG, transthoracic echocardiography (TTE), 6-minute walk test (6MWT) and treadmill test were performed in all patients during cardiac rehabilitation. The CR program included all core components recommended by the European Society of Cardiology. At baseline an exercise treadmill test (ETT) was performed to tailor the CR program to the patient's exercise capacity. The rehabilitation program included interval training on an ergometer, group and individualized, supervised physical training, as well as a psychological program, including group therapy and relaxation sessions. Moreover, educational sessions on lifestyle modification and coronary risk factors control were included in the program.

\section{Endpoints}

Follow-up data, including exact dates of deaths, MI, and repeat hospitalization for $\mathrm{HF}$, were obtained from the health insurer ( $\mathrm{Na}$ tional Health Fund). The MACE were defined as a composite of all-cause mortality, recurrent myocardial infarction, and hospitalization for HF. Hospitalization for HF was defined as admission to a health care facility lasting $>24 \mathrm{~h}$ due to worsening of symptoms of $\mathrm{HF}$ and followed by specific HF treatment (regardless of the cause of decompensation).

\section{Ethics}

The study protocol was approved by the Ethics Committee of the Medical University of Silesia in Katowice.

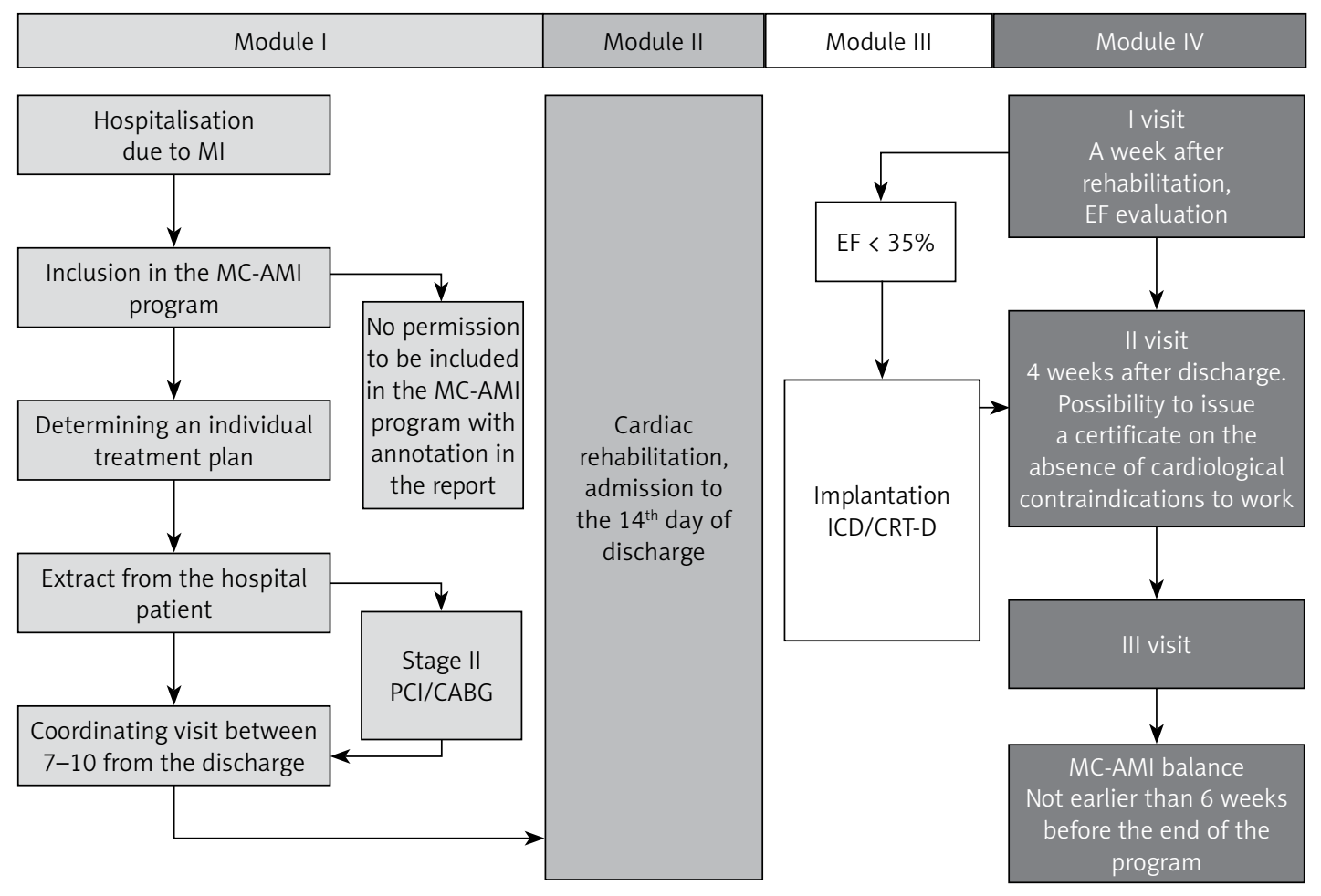

Figure 1. MC-AMI (KOS-zawał) flowchart 
K. Wita, A. Kułach, M. Wita, M.T. Wybraniec, K. Wilkosz, M. Polak, M. Matla, Ł. Maciejewski, J. Fluder, B. Kalańska-Łukasik, T. Skowerski, S. Gomułka, K. Szydło

Table I. Baseline characteristics in unmatched study groups $(n=1782)$

\begin{tabular}{|c|c|c|c|c|}
\hline \multirow[t]{2}{*}{$\begin{array}{l}\text { Parameter } \\
\text { Age [years] }\end{array}$} & $\begin{array}{l}\text { Unmatched study group } \\
\qquad \begin{array}{l}N=719 \\
\text { Mean } \pm \text { SD or } \\
\text { median (1Q-3Q) or } \\
n(\%)\end{array}\end{array}$ & \multicolumn{2}{|c|}{$\begin{array}{l}\text { Unmatched control group } \\
\qquad N=1063 \\
\text { Mean } \pm \text { SD or } \\
\text { median }(1 \mathrm{Q}-3 \mathrm{Q}) \text { or } \\
n(\%)\end{array}$} & \multirow[t]{2}{*}{$\begin{array}{l}P \text {-value } \\
<0.0001^{\prime}\end{array}$} \\
\hline & $65.97 \pm 10.55 \quad 66(59-77)$ & $68.61 \pm 11.27$ & $68(60-76)$ & \\
\hline LVEF (\%) & $45.74 \pm 10.64 \quad 48(39-55)$ & $44.01 \pm 11.57$ & $48(36-55)$ & $0.001^{\prime}$ \\
\hline Female sex & $220(30.6)$ & \multicolumn{2}{|c|}{$361(33.9)$} & $0.146^{\prime \prime}$ \\
\hline History of CHD & 351 (48.9) & \multicolumn{2}{|c|}{519 (48.9) } & $0.995^{\prime \prime}$ \\
\hline Arterial hypertension & $564(78.6)$ & \multicolumn{2}{|c|}{$881(82.8)$} & $0.030^{\prime \prime}$ \\
\hline Diabetes mellitus & $227(31.6)$ & \multicolumn{2}{|c|}{$338(31.8)$} & $0.925^{\prime \prime}$ \\
\hline Hyperlipidemia & $490(68.2)$ & \multicolumn{2}{|c|}{$792(74.4)$} & $0.001^{\prime \prime}$ \\
\hline Previous stroke & $41(5.7)$ & \multicolumn{2}{|c|}{$96(9.0)$} & $0.010^{\prime \prime}$ \\
\hline CKD & $120(16.7)$ & \multicolumn{2}{|c|}{$26.6(26.6)$} & $0.001^{\prime \prime}$ \\
\hline Smoking & $293(40.8)$ & \multicolumn{2}{|c|}{$479(451)$} & $0.087^{\prime \prime}$ \\
\hline Previous STEMI & $97(13.5)$ & \multicolumn{2}{|c|}{$165(5.5)$} & $0.246^{\prime \prime}$ \\
\hline Previous NSTEMI & $116(16.2)$ & \multicolumn{2}{|c|}{$179(16.8)$} & $0.707^{\prime \prime}$ \\
\hline Previous PCl & $219(30.5)$ & \multicolumn{2}{|c|}{$310(29.1)$} & $0.555^{\prime \prime}$ \\
\hline Previous CABG & $80(11.1)$ & \multicolumn{2}{|c|}{148 (13.9) } & $0.084^{\prime \prime}$ \\
\hline NSTEMI presentation & $482(67.1)$ & \multicolumn{2}{|c|}{$733(68.8)$} & $0.401^{\prime \prime}$ \\
\hline STEMI presentation & $236(32.9)$ & \multicolumn{2}{|c|}{$331(30.2)$} & $0.337^{\prime \prime}$ \\
\hline Multivessel disease & $433(60.3)$ & \multicolumn{2}{|c|}{$746(70.1)$} & $0.001^{\prime \prime}$ \\
\hline \multicolumn{5}{|c|}{ Medication at discharge: } \\
\hline ASA & $719(100)$ & 1063 & 100) & - \\
\hline P2Y12 inhibitor & 704 (97.9) & 1030 & $6.9)$ & $0.19^{\prime \prime}$ \\
\hline$\beta$-Blockers & $632(87.9)$ & 920 & $6.5)$ & $0.40^{\prime \prime}$ \\
\hline ACE-I & $654(91.0)$ & 940 & 8.4) & $0.09^{\prime \prime}$ \\
\hline Statins & $701(97.5)$ & 102 & 96) & $0.08^{\prime \prime}$ \\
\hline
\end{tabular}

'Mann-Whitney U test, "Pearson $\chi^{2}$ test. CAD - coronary artery disease, $M I-$ myocardial infarction, $P C l-$ percutaneous coronary intervention, CABG - coronary artery bypass grafting, CHD - coronary heart disease, CKD - chronic kidney disease, STEMI - ST-elevation myocardial infarction, NSTEMI - non-ST-elevation myocardial infarction, LVEF - left ventricular ejection fraction, SD - standard deviation, ACE-I angiotensin converting enzyme inhibitors, ASA - acetylsalicylic acid.

\section{Statistical analysis}

Statistical analysis was performed with SPSS v.25.0 software (IBM Corp, Armonk, NY, USA). First, $1: 1$ propensity score matching using the nearest neighbor method was implemented in order to compensate for the imbalance in terms of baseline covariates between MC-AMI and the control group. The overall Hansen and Bowers balance test showed good case alignment $(p=0.998)$. Out of the initial 1782 patients, a cohort of 1058 patients was incorporated into the final analysis.

Quantitative variables were specified as mean and standard deviation (SD) or median and 25-75 percentile boundaries, whereas qualitative parameters were expressed as number and percentage.
Variable's type of distribution was verified using the Shapiro-Wilk test. Since all continuous variables were non-normally distributed, the twotailed Mann-Whitney $U$ test was used to compare inter-group differences. Qualitative parameters were compared using Pearson's $\chi^{2}$ test. Relative risk (RR) ratios with $95 \%$ confidence intervals $(95 \% \mathrm{Cl})$ were calculated. All the variables with $p<0.1$ in the univariate model were included in the Cox proportional hazards model using backward stepwise Wald's approach. The Kaplan-Meier survival curves for the MC-AMI (group A) and control group (group B) were established and log-rank tests were calculated. A $p$-value of less than 0.05 was regarded as statistically significant. 


\section{Results}

Baseline characteristics of unmatched study groups are presented in Table I. After PSM, we selected a group of 1058 well-balanced pairs (529 in MC-AMI group and 529 in control) with a good bias reduction in most of the parameters (Table II). The incidence of congestive heart failure at baseline was similar in study and control cohorts (44.6\% vs. $46.5 \%$; $p=0.537$ ).

In a 3-month follow-up the occurrence of the MACE composite endpoint was almost twice as common in the control as in the study group (4.9\% vs. $8.9 \%, p=0.012$ ), as shown in Table III and in Kaplan-Meier curves (Figure 2). Death, recurrent $\mathrm{MI}$ and hospitalization for HF were more common in the control group, but the difference was not statistically significant (Table III).

Multivariable Cox regression analysis revealed MC-AMI participation to be inversely associated with the occurrence of MACE at 3 months (HR = $0.476,95 \% \mathrm{Cl}: 0.283-0.799, p<0.005)$. Also, older age (1.037/year; $95 \% \mathrm{Cl}: 1.007-1.056)$, male sex
$(\mathrm{HR}=0.54 ; 95 \% \mathrm{Cl}: 0.31-0.95$ for female), history of unstable angina ( $\mathrm{HR}=3.15 ; 95 \% \mathrm{Cl}: 1.68-5.91)$, peripheral artery disease $(\mathrm{HR}=2.17,95 \% \mathrm{Cl}$ : 1.24-3.79), peri-MI atrial fibrillation $(H R=1.87$, 95\% Cl: $1.06-3.23)$ and diabetes $(H R=1.58$, $95 \% \mathrm{Cl}: 0.97-2.52)$ were associated with the primary endpoint.

Almost all patients in the matched study group (520 out of 529 ; $98.3 \%$ ) were enrolled in an early cardiac rehabilitation (ECR) program; 56.1\% (297 out of 529 patients) were qualified for in-hospital rehabilitation, while $42.2 \%$ (223 out of 529 patients) attended an outpatient CR program. In the control group, only 75 out of 529 subjects (14.2\%) participated in CR (in-hospital CR, 63 patients; outpatient $C R, 12$ patients), which was significantly fewer than in the MC-AMI group $(p<0.001)$

\section{Discussion}

Despite good results of medical and interventional treatment of $\mathrm{AMI}$ and low in-hospital mortality, there is an emerging need for compre-

Table II. Baseline characteristics of two study groups after propensity score matching

\begin{tabular}{|c|c|c|c|c|}
\hline Parameter & $\begin{array}{c}\text { Total } \\
N=1058 \\
\text { Mean } \pm \text { SD or } \\
\text { median }(1 Q-3 Q) \text { or } \\
n(\%)\end{array}$ & $\begin{array}{l}\text { Matched study group } \\
\qquad N=529 \\
\text { Mean } \pm \text { SD or } \\
\text { median (1Q-3Q) or } \\
n(\%)\end{array}$ & $\begin{array}{l}\text { Matched control group } \\
\qquad \begin{array}{c}N=529 \\
\text { Mean } \pm \text { SD or } \\
\text { median }(1 Q-3 Q) \text { or } \\
n(\%)\end{array}\end{array}$ & $P$-value \\
\hline Age [years] & $66.37 \pm 10.94 \quad 66(59-75)$ & $66.36 \pm 10.5366(59-74)$ & $66.40 \pm 11.3467(59-75)$ & $0.846^{\prime}$ \\
\hline LVEF (\%) & $45.54 \pm 10.89 \quad 48(40-55)$ & $45.76 \pm 10.84 \quad 48(40-55)$ & $45.33 \pm 10.9548(38-55)$ & $0.574^{\prime}$ \\
\hline $\mathrm{eGFR}\left[\mathrm{ml} / \mathrm{min} / 1.73 \mathrm{~m}^{2}\right]$ & $73.17 \pm 19.4179(63-90)$ & $73.87 \pm 18.1479(63-90)$ & $72.46 \pm 20.6178(62-90)$ & $0.815^{\prime}$ \\
\hline Female sex & $341(32.2)$ & $167(31.6)$ & $174(32.9)$ & $0.645^{\prime \prime}$ \\
\hline CHD & $548(51.8)$ & $270(51.0)$ & $278(52.6)$ & $0.623^{\prime \prime}$ \\
\hline Arterial hypertension & $852(80.5)$ & $424(80.2)$ & $428(80.9)$ & $0.756^{\prime \prime}$ \\
\hline Diabetes mellitus & $339(32.0)$ & $168(31.8)$ & $171(32.3)$ & $0.843^{\prime \prime}$ \\
\hline Hyperlipidemia & $778(73.5)$ & $391(73.9)$ & $387(73.2)$ & $0.780^{\prime \prime}$ \\
\hline Previous stroke & $58(5.5)$ & $26(4.9)$ & $32(6.0)$ & $0.418^{\prime \prime}$ \\
\hline CKD & $188(17.8)$ & $92(17.4)$ & $96(18.1)$ & $0.748^{\prime \prime}$ \\
\hline Smoking & $443(41.9)$ & $215(40.6)$ & $228(43.1)$ & $0.418^{\prime \prime}$ \\
\hline Previous STEMI & $166(15.7)$ & $81(15.3)$ & $85(16.1)$ & $0.735^{\prime \prime}$ \\
\hline Previous NSTEMI & 197 (18.6) & $93(17.6)$ & $104(19.7)$ & $0.385^{\prime \prime}$ \\
\hline Previous $\mathrm{PCl}$ & $345(32.6)$ & $168(31.8)$ & $177(33.5)$ & $0.555^{\prime \prime}$ \\
\hline Previous CABG & $129(12.2)$ & $63(11.9)$ & $66(12.5)$ & $0.778^{\prime \prime}$ \\
\hline NSTEMI presentation & $716(67.7)$ & $352(66.5)$ & $364(68.8)$ & $0.430^{\prime \prime}$ \\
\hline STEMI presentation & $330(31.2)$ & $170(32.1)$ & $160(30.2)$ & $0.507^{\prime \prime}$ \\
\hline Multivessel disease & $604(57.1)$ & $294(55.6)$ & $310(58.6)$ & $0.320^{\prime \prime}$ \\
\hline
\end{tabular}

Mann-Whitney U test; "Pearson $\chi^{2}$ test. CAD - coronary artery disease, $\mathrm{MI}$ - myocardial infarction, $P C l$ - percutaneous coronary intervention, CABG - coronary artery bypass grafting, CHD - coronary heart disease, CKD - chronic, kidney disease, STEMI - ST-elevation myocardial infarction, NSTEMI - non-ST-elevation myocardial infarction, LVEF - left ventricular ejection fraction, SD - standard deviation. 
K. Wita, A. Kułach, M. Wita, M.T. Wybraniec, K. Wilkosz, M. Polak, M. Matla, Ł. Maciejewski, J. Fluder, B. Kalańska-Łukasik, T. Skowerski, S. Gomułka, K. Szydło

Table III. Comparison of study endpoints between MC-AMI group and control group in 3-month observation (propensity score matching)

\begin{tabular}{|lccccccc|}
\hline Parameter & $\begin{array}{c}\text { Total } \\
N=1058 \\
n(\%)\end{array}$ & $\begin{array}{c}\text { MC-AMI } \\
\text { group } \\
N=529 \\
n(\%)\end{array}$ & $\begin{array}{c}\text { Control } \\
\text { group } \\
N=529 \\
n(\%)\end{array}$ & RR & 95\% Cl & NNT & $P$-value* \\
\hline All-cause mortality & $19(1.8)$ & $7(1.3)$ & $12(2.3)$ & 0.583 & $0.232-1.470$ & 105.8 & 0.247 \\
\hline Hospitalization for HF & $31(2.9)$ & $12(2.3)$ & $19(3.6)$ & 0.632 & $0.310-1.288$ & 75.6 & 0.202 \\
\hline Myocardial infarction & $25(2.4)$ & $9(1.7)$ & $16(3.0)$ & 0.563 & $0.251-1.262$ & 75.6 & 0.157 \\
\hline MACE & $73(6.9)$ & $26(4.9)^{\#}$ & $47(8.9)$ & 0.553 & $0.348-0.879$ & 25.2 & 0.012 \\
\hline
\end{tabular}

${ }^{\star}$ Two-tailed Pearson's $\chi^{2}$ test; MACE - major adverse cardiovascular events. "Number of patients with at least one MACE; in 2 patients 2 endpoints occurred. This explains why the total number of MACE is lower than the sum of all endpoints.

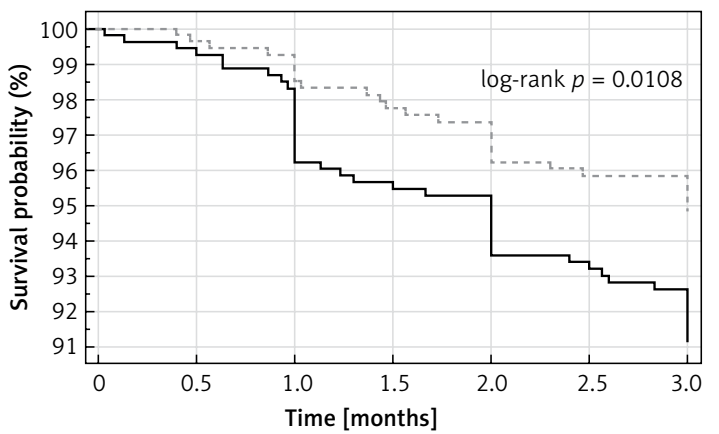

Number at risk

Group 0

\begin{tabular}{rrrrrrr}
529 & 525 & 509 & 505 & 495 & 493 & 0 \\
Group 1 & & & & & & \\
529 & 527 & 521 & 517 & 509 & 507 & 0 \\
& \multicolumn{7}{c}{ MC-AMI ... 0} & -1
\end{tabular}

Figure 2. Kaplan-Meier survival curves - MACE in 3-month observation

hensive post-discharge medical care to reduce long-term adverse events and to improve patients' exercise capacity and quality of life.

MC-AMI is the first nation-wide, structured, comprehensive and supervised care system, close to the optimal and guideline-recommended management, which is hardly met in real-world conditions. We hereby present data showing the benefit of MC-AMI participants with regard to reduction of hard clinical endpoints. Primarily, we have found a $45 \%$ relative risk reduction of MACE in 3-month observation. To the best of our knowledge, this is the first study to address the relation between complex care strategy and hard clinical endpoints in post-AMI patients.

In our cohort, in-hospital mortality, medical therapy and interventional treatment were similar in both groups. One limitation of the study is that the cohorts compared are non-contemporaneous. However, neither treatment guidelines nor local polices had changed over the period when the analysis was performed. The alternative approach for retrospective analysis would be to compare the data of MC-AMI participants to those who did not consent to MC-AMI. From our experience, however, the patients who refused to consent were quite a different (and heterogeneous) group, compared to those who consented to participation, and compared to a general population of MI survivors. While almost all patients qualified for in-hospital CR agreed to participate, patients qualified for outpatient CR presented with more obstacles (difficulty with everyday traveling to the CR facility, distance from home to CR etc.). Furthermore, despite intensive education, patients with milder symptoms and in-hospital course of the MI were more difficult to convince and to show them benefits coming from CR. Another group of patients who did not agree were the elderly and fragile patients who were either unable or unwilling to participate. Finally, comparing MC-AMI patients to a similar cohort from one year before allowed for a reasonably powered analysis, which would not have been possible if we had chosen the non-consenting cohort ( $n=423$ over the analyzed period). Thus, we decided to match our study group to a cohort from a similar period, but 1 year before.

As stated, the patients in the MC-AMI and control group were matched to compensate the imbalance in risk factors and major MI-related clinical data. Thus, the MACE reduction is attributable to the management in the post-discharge period.

According to the current guidelines, post-MI patients should participate in a cardiac rehabilitation program [13]. In a large meta-analysis, Anderson et al. [14] revealed that CR reduces cardiovascular mortality by $22 \%$, but does not affect all-cause mortality. In our study, where participation in CR was one of the crucial factors differentiating study and control groups, we also did not observe longterm all-cause mortality reduction, but participation in MC-AMI reduced MACE by $45 \%$ as soon as in 3 months.

In the most complex meta-analysis by Kabboul et al. [15] (148 studies, 50965 patients), in which not only exercise capacity but also nutritional counseling, risk factor modification, psychosocial management, and patient education were ana- 
lyzed, the authors found that different components of a complex CR program have a different effect on adverse events reduction. Not only physical training but also psychosocial management and patient education were found to influence the endpoints. In our study, the above-mentioned components were included in the program, and are presumed to have participated in MACE reduction by improving compliance.

In a multivariable Cox regression model participation in MC AMI was one of the strongest negative predictors of MACE $(H R=0.48, p<0.001)$. As $M C-A M I$ is the first comprehensive post-discharge management program for AMI patients, there are no data to compare our results to in the literature. We can, however, compare them to studies assessing effects of the components of MC-AMI, particularly CR.

In the CROS meta-analysis, mortality reduction for post-ACS CR participants was $0.49-0.84$ in retrospective studies and $0.20-0.69$ for prospective ones [16]. In a large Dutch cohort, CR significantly improved 4-year survival with an HR of 0.65 (95\% Cl: 0.56-0.77), with the largest benefit observed for patients who underwent CABG and/or valve surgery ( $\mathrm{HR}=0.55,95 \% \mathrm{Cl}: 0.42-0.74)$ [17]. In our study, the benefit from MC-AMI was measured primarily in MACE reduction and, although it is not possible to compare it directly, seems higher than in most retrospective studies in the CROS meta-analysis.

In our opinion it is the complex approach in MC-AMI that warrants better adverse events reduction over a shorter time. It seems, however, that in a 3-month observation the most important factors are cardiac rehabilitation and close, supervised follow-up. Importantly, such an approach has a good perception among participants, as recently reported by Feusette et al. [18].

In our analysis, besides MC-AMI participation, older age, male sex, history of unstable angina, peripheral artery disease, peri-MI atrial fibrillation, and diabetes were found to be related to the risk of MACE. The observations are consistent with the literature; there is however a large variety of factors taken into the analysis in different studies.

The observation is a retrospective cohort study, so only a statistical association rather than causal relationships could be confirmed. Moreover, the analysis was performed in a single center cohort. A multicenter analysis would provide more insight into local differences in implementation of the MC-AMI program in everyday practice. Finally, despite very encouraging results of 3-month observation, a longer follow-up will be necessary to prove a long-term benefit of the program.

In conclusion, participation in MC-AMI - the first comprehensive in-hospital and post-dis- charge care for AMI patients - improves prognosis and reduces the MACE rate by $45 \%$ as soon as in 3-month follow-up.

\section{Conflict of interest}

The authors declare no conflict of interest.

\section{References}

1. Gierlotka M, Zdrojewski T, Wojtyniak B, et al. Incidence, treatment, in-hospital mortality and one-year outcomes of acute myocardial infarction in Poland in 2009-2012-nationwide AMI-PL database. Kardiol Pol 2015; 73: 142-58.

2. Schmidt M, Jacobsen JB, Lash TL, et al. 25 years trends in first hospitalization for acute myocardial infarction, subsequent short and long term mortality, and the prognostic impact of sex and comorbidity: a Danish nationwide cohort study. BMJ 2012; 344: e356.

3. Smolina K, Wright FL, Rayner M, et al. Long-term survival and recurrence after acute myocardial infarction in England, 2004 to 2010. Circ Cardiovasc Qual Outcomes 2012; 5: 532-40.

4. Freisinger E, Fuerstenberg T, Malyar NM, et al. German nationwide data on current trends and management of acute myocardial infarction: discrepancies between trials and real-life. Eur Heart J 2014; 35: 979-88.

5. Jankowski P, Czarnecka D, Badacz L, et al. Practice setting and secondary prevention of coronary artery disease. Arch Med Sci 2018; 14: 979-87.

6. Townsend N, Wilson L, Bhatnagar P, et al. Cardiovascular disease in Europe: epidemiological update 2016. Eur Heart J 2016; 37: 3232-45.

7. Gale CP, Allan V, Cattle BA, et al. Trends in hospital treatments, including revascularisation, following acute myocardial infarction, 2003-2010: a multilevel and relative survival analysis for the National Institute for Cardiovascular Outcomes Research (NICOR). Heart 2014; 100: 582-9.

8. Jankowski P, Czarnecka D, Wolfshaut-Wolak R, et al. Secondary prevention of coronary artery disease in contemporary clinical practice. Cardiol J 2015; 22: 219-26.

9. Kotseva K, Wood D, De Bacquer D, et al. EUROASPIRE IV: a European Society of Cardiology survey on the lifestyle, risk factor and therapeutic management of coronary patients from 24 European countries. Eur J Prev Cardiol 2016; 23: 636-48.

10. Piepoli M, Hoes A, Agewall S, et al. 2016 European Guidelines on cardiovascular disease prevention in clinical practice: The Sixth Joint Task Force of the European Society of Cardiology and Other Societies on Cardiovascular Disease Prevention in Clinical Practice (constituted by representatives of 10 societies and by invited experts) Developed with the special contribution of the European Association for Cardiovascular Prevention \& Rehabilitation. Eur Heart J 2016; 37: 2315-81.

11. Jankowski P, Gąsior M, Gierlotka M, et al. Coordinated care after myocardial infarction. The statement of the Polish Cardiac Society and the Agency for Health Technology Assessment and Tariff System. Kardiol Pol 2016; 74: 800-11.

12. Narodowy Fundusz Zdrowia. Zarządzenie Nr 38/2017/ DSOZ Prezesa Narodowego Funduszu Zdrowia z dnia 29 maja 2017 r. w sprawie określenia warunków zawierania i realizacji umów w rodzaju leczenie szpitalne 
K. Wita, A. Kułach, M. Wita, M.T. Wybraniec, K. Wilkosz, M. Polak, M. Matla, Ł. Maciejewski, J. Fluder, B. Kalańska-Łukasik, T. Skowerski, S. Gomułka, K. Szydło

- świadczenia kompleksowe. Online referencing, http:// www.nfz.gov.pl/zarzadzenia-prezesa/zarzadzenia-prezesa-nfz/zarzadzenie-nr-382017dsoz,6578.html

13. Ibanez B, James S, Agewall S, et al. 2017 ESC Guidelines for the management of acute myocardial infarction in patients presenting with ST-segment elevation: The Task Force for the management of acute myocardial infarction in patients presenting with ST-segment elevation of the European Society of Cardiology (ESC). Eur Heart J 2018; 39: 119-77.

14. Anderson L, Thompson DR, Oldridge N, et al. Exercise-based cardiac rehabilitation for coronary heart disease (Review). Cochrane Database Syst Rev 2016; 1 : CD001800.

15. Kabboul N, Tomlinson G, Francis T, et al. Comparative effectiveness of the core components of cardiac rehabilitation on mortality and morbidity: a systematic review and network meta-analysis. J Clin Med 2018; 7: 514-34

16. Rauch B, Davos CH, Doherty P, et al. The prognostic effect of cardiac rehabilitation in the era of acute revascularisation and statin therapy: a systematic review and meta-analysis of randomized and non-randomized studies - The Cardiac Rehabilitation Outcome Study (CROS). Eur J Prev Cardiol 2016; 23: 1914-39.

17. De Vries H, Kemps HM, van Engen-Verheul MM, et al. Cardiac rehabilitation and survival in a large representative community cohort of Dutch patients. Eur Heart J 2015; 36: 1519-28.

18. Feusette P, Gierlotka M, Krajewska-Redelbach I, et al, Comprehensive, coordinated care after myocardial infarction KOS-Zawat - the patients' perspective. Kardiol Pol 2019; 77: 568-70. 